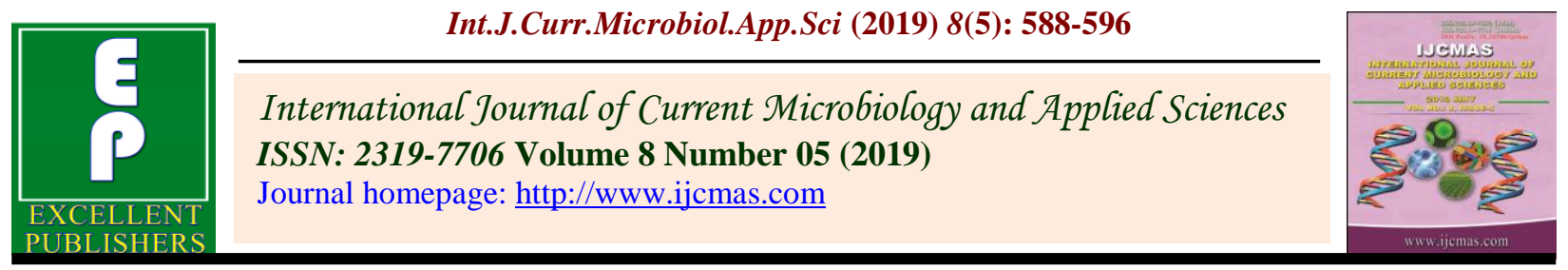

\title{
Effect of Extenders Containing Glycerol and Egg Yolk on Motility and Viability of Chilled Ram Semen collected during Non-Breeding Season
}

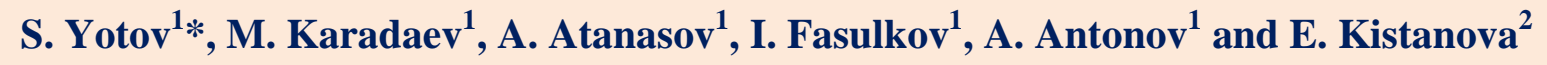 \\ ${ }^{1}$ Department of Obstetrics, Reproduction and Reproductive Disorders, Faculty of Veterinary \\ Medicine, Trakia University, 6000 Stara Zagora, Bulgaria \\ ${ }^{2}$ Bulgarian Academy of Sciences, Institute of Biology and Immunology of Reproduction, 1113 \\ Sofia, Bulgaria \\ *Corresponding author
}

\begin{tabular}{|l|}
\hline Ke y w or d s \\
Ram, Chilled \\
semen, Extender, \\
Glycerol, Egg yolk, \\
Time of storage \\
\hline Article Info \\
\hline Accepted: \\
07 April 2019 \\
Available Online: \\
10 May 2019 \\
\hline \hline
\end{tabular}

A B S T R A C T

The aim of this study was to evaluate the effect of Tris-based extenders containing glycerol and egg yolk on the motility and viability of chilled ram semen collected during non-breeding season. Nine ejaculates from three healthy rams in non-breeding season were collected by artificial vagina method. The semen was diluted with Steridyl (ST), Triladyl (TRY) or Tris-based extender containing $5 \%$ glycerol and 5\% egg-yolk (TGGY) to a final concentration $200 \times 10^{9}$ spermper ml. Semen samples $(n=9)$ for each extender were stored at $5^{\circ} \mathrm{C}$ for 72 hours. Motility and viability were evaluated at $0,6,24,48$ and $72 \mathrm{~h}$ of storage. The results were statistically processed and the influence of extender and time of storage were recorded. After $6 \mathrm{~h}$ of storage the initial motility and viability did decrease $(\mathrm{P}<0.05)$ in all extenders but until $48 \mathrm{~h}$ significant differences among values for the same interval were not determined. At $72 \mathrm{~h}$ the values for ST and TGGY were increased $(\mathrm{P}<0.05)$ compared to TRY, but rather unsatisfactory. The increased time of storage was negatively correlated with both indicators in all extenders $(\mathrm{P}<0.05)$. In conclusion, Tris-based extenders containing glycerol and egg yolk demonstrated good protective effect on ram semen collected during the non-breeding season and stored at $5^{\circ} \mathrm{C}$. The type of extender had no influence on sperm motility and viability until $48 \mathrm{~h}$ of storage, while the time of storage significantly $(\mathrm{P}<0.05)$ affected the semen parameters.

\section{Introduction}

The reproductive management in intensive sheep breeding includes artificial insemination of sheep in several breeding periods per year. The distribution of semen form high producing rams of a long distance, preservation for extended period or repeated artificial insemination (AI) of a large number of sheep is connected with chilling or freezing process. The chilled semen is shown as alternative of the frozen semen by different authors (Salmon and Maxwell, 2000; Fernandez-Abella et al., 2003; Abulizi et al., 2012). Crucial factors for high conception rate after insemination with chilled semen are use of effective extender, appropriate dilution rate and time for semen preservation, insemination 
in optimal time and deep cervical semen deposition (Maxwell and Salamon, 1993; Menchaca et al., 2005).

Supplementing of glycerol and egg yolk to Tris-based extenders protects spermatozoa from cold shock during preservation in low temperatures $\left(0-5^{0} \mathrm{C}\right)$ (Morrier et al., 2002; Gill et al., 2003; Stefanov et al., 20015; Rekha et al., 2016). Glycerol is penetrating protector which interacts with bound proteins and glycoproteins, increases the bioenergetic requirements of the sperm cells and is added to extender at concentrations of 3\%-7\% (Hammerstedt et al., 1990; Gill et al., 2011; Pelufo et al., 2015). Anegative impact of increased concentration of glycerol on the sperm membrane integrity with potential toxic effect is reported by Abdelhakeam et al., (1991) and Holt (2000). In contrast, no detrimental impact of egg yolk extender with $7 \%$ glycerol on the semen quality during preservation at temperature $5^{\circ} \mathrm{C}$ for 48 hours is showed by Morrier et al., (2002) and Purdy et al., (2010). Egg yolk is non-penetrating protector which is supplemented to extender in concentration from $5 \%$ to $20 \%$. It is intended for maintenance of sperm motility, reduction the loss of acrosomal enzymes and protection of the mitochondrial membranes of sperm during chilling (White, 1993; Salamon and Maxwell, 2000). A few studies (MarcoJiménez et al., 2004; Alcay et al., 2015; García et al., 2017) state influence of source and concentration of egg yolk on the semen quality during cooling or freezing. Nevertheless, clear standpoint about effect of different concentrations of both protectors on ram semen quality is not presented.

Other important factor connected with quality of chilled ram semen intended for artificial insemination is the time of storage. The main changes observed during semen preservation include reduction in motility and viability of sperm cells (Maxwell and Watson, 1996;
Salmon and Maxwell, 2000). Gill et al., (2011) observed fast decrease of the initially sperm motility during the first $24 \mathrm{~h}$, however, no significant difference in viability among ram semen stored at $4^{0} \mathrm{C}$ for $72 \mathrm{~h}$ and fresh semen was detected by Abulizi et al., (2012). Irrespective of great number of investigations, the data about effect of extenders containing glycerol and of egg yolk and time of storage on quality of chilled ram semen are conflicting.

The aim of this study was to evaluate the effect of Tris-based extenders containing glycerol and egg yolk on the motility and viability of chilled ram semen collected during non-breeding season.

\section{Materials and Methods}

\section{Experimental animals, semen collection, dilution and chilling}

The study was carried out with three clinical healthy rams Pleven Black head breed and cross-breeds, 4-6 years old, $60-70 \mathrm{~kg}$ body weight) housed in the uniform technology, immunoprophylaxis regimen and feeding with water intake at libitum. The animals were reared into individual yards at the small ruminant unit, located at N 42.25 and E 25.38. Before semen collection a physical examination of donors was performed. Investigation was conducted during the nonbreeding season (February-March) in accordance with the standard requirements for human attitude and animal protection.

From each ram 3 ejaculates seven days apart were collected by the artificial vagina method in presence of a teaser sheep. All ejaculates $(n=9)$ were transported to the laboratory within 5 minutes, placed on a water bath at $35^{\circ} \mathrm{C}$ and submitted to primary assessment. The volume was measured by graduated pipette and mass motility was evaluated on 
the base of wave motion (scale 0-5, Evans and Maxwell, 1987). The sperm concentration $\left(\mathrm{x} 10^{9} / \mathrm{ml}\right)$ was determined by Photometer SpermaCue (Minitübe, Germany), calibrated for small ruminants semen. Only ejaculates with normal color and transparency, volume > $1 \mathrm{ml}$, concentration $>1 \times 10^{9} / \mathrm{ml}$, mass motility $>3.5$ and abnormal sperms $<20 \%$ were included in the experiments.

The semen samples were diluted with Trisbased extenders containing glycerol and egg yolk in different concentration- Steridyl (ST), Triladyl (TRY) (Minitübe, Germany) and Tris-glucose-glycerol-egg yolk extender (TGGY) adapted to Evans and Maxwell (1987) prescription. All chemicals for TGGY preparation were from Alfa Aesar (Thermo Fisher Scientific GmbH, Germany). Steridyl and Triladyl are commercial extenders with base of Tris, citric acid, sugar, buffers, glycerol, purest water and antibiotics. Steridyl is extender which contains sterilized egg yolk in the concentrate. According to manufacturer guidance $7.5 \mathrm{ml}$ of distilled water were added to $5 \mathrm{ml}$ of concentrate. Triladyl extender was prepared by mixing of Triladyl-concentrate, aqua bidestillata and fresh egg yolk in a ratio 1:3:1. Tris-glucose-glycerol-egg yolk extender consisted of low (5\%) concentrations of glycerol and fresh egg yolk. The stock solution for TGGY included Trishydroxymethylaminomethane $3.63 \mathrm{~g}$, glucose $0.5 \mathrm{~g}$, citric acid $1.99 \mathrm{~g}$ and aqua bidestillata $100 \mathrm{ml}$. The completed extender was prepared by supplementing of $5 \%$ glycerol (v/v), 5\% egg-yolk (v/v) to a stock solution and gentamycin $50 \mu \mathrm{g} / \mathrm{ml}$. After adding of egg yolk, Triladyl and TGGY extenders were handled by vortex mixer for 10 minutes and filtered by filter paper. Before semen collection all semen extenders were placed on a water bath at $35^{\circ} \mathrm{C}$.

Immediately after the primary assessment each ejaculate was split in three equal parts placed in pre-warmed plastic tubes. Each of them was diluted with one of abovementioned extenders in a ration 1:1 and kept on a water bath 5 minutes for adaptation of semen to extender. Additional dilution until adjustment of the sperm concentration to $200 \times 10^{6}$ cells per $\mathrm{ml}$ was performed. Semen samples in aliquots diluted by ST (n=9), TRY $(n=9)$ and TGGY $(n=9)$ were placed in a Beher glass with $300 \mathrm{ml}$ pure water at $35^{\circ} \mathrm{C}$ and stored in a refrigerator at $5^{\circ} \mathrm{Cfor} 72$ hours.

\section{Semen evaluation}

Motility and viability of the spermatozoa were evaluated at $0,6,24,48$ and 72 hours during storage at $5^{\circ} \mathrm{C}$.

Motility was estimated subjectively by microscopic examination using of MoticImage Plus Digital System (Motic China Group Ltd, 2001-2004), including amicroscope, objectives with different magnification, digital camera and relevant software. Immediately before examination the semen samples were gently mixed and $5 \mu \mathrm{L}$ drop was placed on warmed at $37^{\circ} \mathrm{C}$ slide, covered with $20 \mathrm{~mm} \times 20 \mathrm{~mm}$ coverslip and observed at 200 and $400 \times$ by qualified operator. The average value of three consecutive observations indifferent microscopic fields was calculated asa final motility (Ax et al., 2000).

Viability was assessed by one step eosinnigros in staining technique (Mortimer, 1994). The smear was prepared by mixing of 2 equal drops of semen and staining solution $(0.67 \%$ eosin-Y and $10 \%$ nigrosin dissolved in $0.9 \%$ sodium chloride in distilled water). After incubation of the mixture at room temperature $\left(20^{\circ} \mathrm{C}\right)$ for 30 seconds it was placed on a warm slide, spreading with a second slide and dried on air. The viability was assessed by counting 200 cells under microscope at magnification 200-400x. Sperm cells that 
were unstained (white) were accepted as alive, whereas stained (pinkor red colouration) were considered to be dead.

\section{Statistical analysis}

The results were processed by statistical program Statistica version 7.0 (Stat-Soft., 1984-2000 Inc., Tulsa, OK, USA). The semen motility and viability were expressed as mean \pm standard deviation (Mean \pm SD). Analysis of variance (ANOVA) and Fisher`s exact test were used for comparison of the means for motility and viability affected by the extender and time of evaluation. The relationship between time of storage and semen quality parameters was determined by correlation analysis and Pearson's coefficients of correlation were calculated. Statistical significance was considered at $\mathrm{P}<0.05$.

\section{Results and Discussion}

In the primary semen assessment differences between ejaculates collected from different donors at the same time and from the same ram for all collections were not detected. Because of that, factors of influence as effects of ram and time of semen collection were excluded.

The mean values for motility during the first evaluation $(0 \mathrm{~h})$ were $80.5 \pm 5.0 \%, 77 \pm 5.8 \%$ and $78 \pm 2.9 \%$ for Steridyl, Triladyl and Trisglucose-glycerol-egg yolk extender, respectively (Fig. 1). Until $6 \mathrm{~h}$ of semen storage no differences $(\mathrm{P}>0.05)$ were registered between the values. Then, the sperm motility decreased rapidly $(\mathrm{P}<0.05)$ but at 24 hand $48 \mathrm{~h}$ was still in ranges $>62 \%$ and $>54 \%$ for all extenders. At $72 \mathrm{~h}$ the motility was unsatisfactory $(33 \pm 5.8 \%$ ST, $22 \pm 6.4 \%$ TRY and 30 \pm 7.6 TGGY) and significant $(\mathrm{P}<0.05)$ lower compared to recorded one in previous evaluations. Significantly influence of type of extender on motility was not determined until $48 \mathrm{~h}$. However, during the final evaluation $(72 \mathrm{~h})$ more motile spermatozoain semen diluted with ST and TGGY than TRY were observed $(\mathrm{P}<0.04)$. The correlation between time of storage and motility was high negative with correlation coefficients $\mathrm{R}=-0.98 \mathrm{P}<0.02, \mathrm{R}=-0.96$ $\mathrm{P}<0.007$ and $\mathrm{R}=-0.94 \quad \mathrm{P}<0.004$ for consequently tested extenders.

The sperm viability determined at $0 \mathrm{~h}$ was similar $(82.3 \pm 2.9 \% \mathrm{ST}, 80.8 \pm 2.3 \% \mathrm{TRY}$ and $80 \pm 2.4 \%$ TGGY) and this tendency continued up to $6 \mathrm{~h}$ (Fig. 2).In all extenders, significant differences $(\mathrm{P}<0.05)$ between viability at $0 \mathrm{~h}$ and $6 \mathrm{~h}$ compared to viability determined at 24,48 or72 hours were detected. Until 24 hit gradually decreased with values of $76.2 \pm 3.6 \%$ for ST, $74.5 \pm 2.7 \%$ for TRY and $74.6 \pm 2.4 \%$ for TGGY. In the next evaluation it was > $70 \%$ for all samples. After $48 \mathrm{~h}$ dramatically drop with values $>50 \%$ for all extenders was registered. Type of extender no affected this parameter until $48 \mathrm{~h}$ of storage. The motility for ST and TGGYat $72 \mathrm{~h}$ was higher $(\mathrm{P}<0.05)$ than obtained for TRY $(46.2 \pm 3.3 \%$ and $42.9 \pm 2.4 \%$ vs. $37.9 \pm 2.8 \%)$. The correlations between time of storage and values of the evaluated parameter were also negative $(\mathrm{R}=$ $0.92 \mathrm{P}<0.02 \mathrm{ST}, \mathrm{R}=-0.89 \mathrm{P}<0.04 \mathrm{TRY}$ and $\mathrm{R}=-0.91 \mathrm{P}<0.03 \mathrm{TGGY})$.

Sperm motility and viability are the most important parameters for semen quality assessment and indicators for male fertility. The motility is directly connected to sperm transport while viability is responsible for potential fertilizing capacity of a sire (Ollero et al., 1996; Kordan et al., 2013). Effective semen extender is shown as a main factor for maintenance of high motility and viability during chilling of semen (Salamon and Maxwell, 2000).

The current study indicated good protective effect of extenders containing glycerol and 
egg yolk on ram semen preserved at temperature $5^{0} \mathrm{C}$. The high motility $(>62 \%)$ and viability (>74\%) up to $24 \mathrm{~h}$ of chilling with insignificant influence of type of extender on the assessed parameters up to 48 $\mathrm{h}$ confirmed this assertion. Related to this, Gil et al.,(2011) reported that a combination of egg yolk-glycerol improve the quality of ram spermatozoa during cooling and might provide extra protection in case of fluctuation of temperatures below $5^{0} \mathrm{C}$. Pelufo et al., (2015) also determined beneficial effect of Tris-glycerol-egg yolk extender on ram semen quality.

The relative increase of motility and viability in semen samples with Steridyl compared to TRY and TGGY can be accepted as advantage of the extender containing egg yolk in concentrate. The differences $(\mathrm{P}<0.05)$ between the parameters in samples extended with ST and TRY at $72 \mathrm{~h}$ supported abovementioned. Increased sperm motility and viability inbull semen diluted bypowdered egg yolk extender was also determined by Ansari et al., (2010). However, no significant differences in motility, plasma membrane integrity, acrosome integrity and DNA integrity between extenders involving lyophilized and fresh egg yolk have stated by Alcay et al., (2015). In contrast, a better effect of ST compared to other extenders in a preservation of bull semen at $5^{\circ} \mathrm{C}$ for $48 \mathrm{~h}$ was registered by Bao-Tarragó (2017). García et al., (2017) reported greater bio-security effect of powdered than fresh clarified egg yolk. Nevertheless, future detailed investigations about influence of different egg yolk sources on the quality of ram semen are necessary.

A positive effect of Triladyl on ram semen preservation has been observed by different authors (Morrier et al., 2002; Rekha et al., 2016; Badi et al., 2018). Morrier et al., (2002) detected no significant effect on the motility parameters or viability of the sperm during storage at $5^{\circ} \mathrm{C}$ for $24 \mathrm{~h}$ in presence or absence of $7 \%$ glycerol in the egg-yolk extender. In our experiment, similar effect was observed until $6 \mathrm{~h}$ of storage, followed by significantly $(\mathrm{P}<0.05)$ decrease of the values. Rekha et al., (2016) showed higher motility than the obtained in this study at $24 \mathrm{~h}$ after chilling $(82.9 \pm 0.3$ vs. $62 \pm 7.6 \%)$. A possible explanation of these discrepancies could be different sperm resistance to low temperatures due to individual properties or different age of the rams. The abovementioned authors collected their ejaculates from Dorset-Polled and Hampshire rams aged from 2 to 7 year and Bangladesh indigenous males aged from 2 to 3 year, whereas our donors were Pleven Blackhead breed and crossbreeds of 4-6 years old. In this regard, Holt et al., (2000) reported that inter-individual differences in sperm "freezability" are genetically inherited and significant effect of age of the rams on initial semen quality and lower resistance of spermatozoa in older rams was recorded by Badi et al., (2018).

Different Tris-based extenders containing concentration of protectors lower than conventional (glycerol > 7\% and egg yolk > $20 \%$ ) has been used for chilling or freezing of ram semen (Abdelhakeam et al., 1991; Valente et al., 2010; Pelufo et al., 2015), but the obtained results are variable. This study shows effect of extender with decreased concentrations (5\%) of glycerol and egg yolk on the motility and viability of chilled ram semen. Abdelhakeam et al., (1991) reported low fertility of ram semen diluted by TESTegg yolk-glucose with $3 \%$ glycerol. Unsatisfactory effect of extender with a low $(4.5 \%)$ concentration of egg yolk on quality of frozen-thawed ram semen and fertility was recorded by Valente et al., (2010). However, the lack of difference between the values until $48 \mathrm{~h}$ of storage was indicative for similarity in a protective effect of all extenders, in spite of lower contents of protectors in TGGY. Additional evidence for good protection of 
extender containing 5\% glycerol and 5\% egg yolk was significant difference $(\mathrm{P}<0.05)$ between the semen quality indicators for TGGY and TRY observed at $72 \mathrm{~h}$ of storage. In accordance with our assertion, Tris-based extender supplemented with $10 \%$ egg yolk, $4 \%$ glycerol and disaccharides has was showed as the best treatment to process the ram ejaculates in freezing (Pelufo et al., 2015).

Fig.1 Sperm motility of chilled semen during storage at temperature $5^{\circ} \mathrm{C}$ for 72 hours

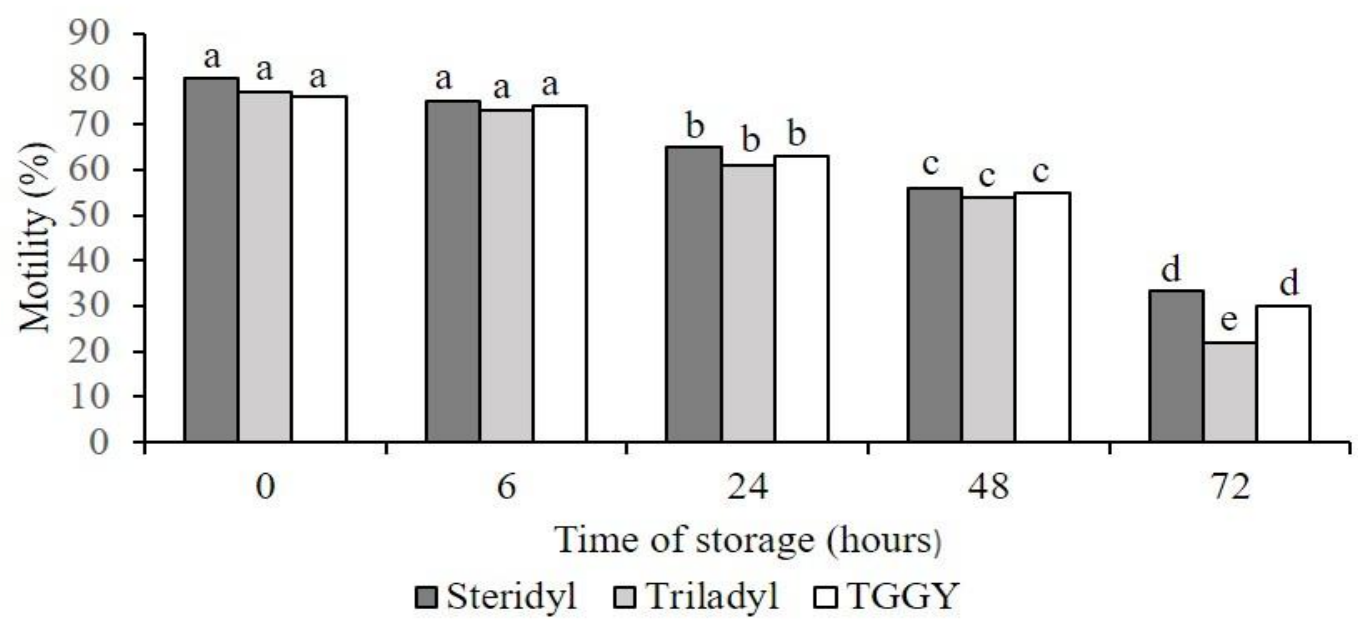

Different letters indicate significant differences $(\mathrm{P}<0.05)$ between values registered for the same and during different hours.

Fig.2 Sperm viability of chilled semen during storage at temperature $5^{\circ} \mathrm{C}$ for 72 hours

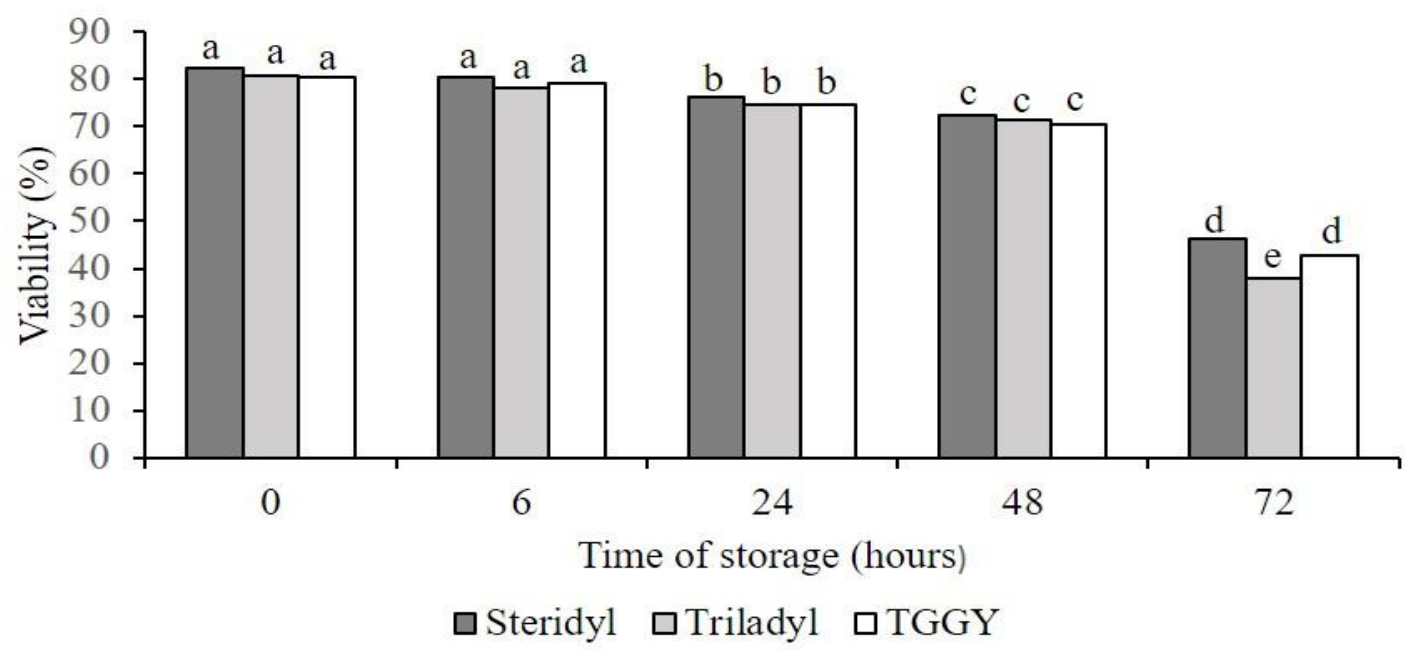

Different letters indicate significant differences $(\mathrm{P}<0.05)$ between values registered for the same and during the different hours.

The time of storage has been defined as factor which significantly or no affected the semen quality during preservation at low temperatures for 3 to 4 days (Salmon and Maxwell, 2000; Pervage et al., 2009; Abulizi et al., 2012; Rekha et al., 2016; Varişli et al., 
2018; Abd-El-Hamid et al., 2019). Salmon and Maxwell (2000) reported that the changes during extended semen preservation may be connected with the accumulation of the toxic products of metabolism, mainly of reactive oxygen species produced by lipid peroxidation of the membranes of sperm cells. The high negative correlation $(\mathrm{P}<0.05)$ between time of storage and the values of both parameters confirmed abovementioned. The current study indicated high sperm motility and viability for all extenders during the first 24 hours in storage at $5^{\circ} \mathrm{C}$. The earlier decrease of sperm motility and viability was in contrast with data for a lack of significant changes in chilled semen stored for 48 (Pervage et al., 2009) or 72 hours (Abulizi et al., 2012). In support of our results was significantly $(\mathrm{P}<0.05)$ lower sperm motility of at $5 \mathrm{~h}$ or $24 \mathrm{~h}$ of storage observed by Abd-ElHamid et al., (2019) and Varişli et al.,(2018). The conflicting results about effect of time of storage on chilled semen quality could be attributed to some differences in the used semen extenders, influence of age and breed of the donors on semen cryotolerance and season of semen collection. A seasonal effect with low semen quality during winter months was registered by Malejane et al., (2014). In this aspect, Rekha et al., (2016) also stated significant $(\mathrm{P}<0.001)$ influence of the preservation time on the semen parameters. Future investigations with a large number of donors, evaluation of more indicators for semen quality and in vivo tests are necessary to clarify fertilizing capacity of chilled ram semen diluted with extenders containing lower concentration of both protectors or different source of egg yolk.

In conclusion, Tris-based extenders containing glycerol and egg yolk demonstrated good protective effect on ram semen collected during the non-breeding season and stored at $5^{\circ} \mathrm{C}$. The type of extender had no influence on sperm motility and viability until $48 \mathrm{~h}$ of storage, but the time of storage significantly $(\mathrm{P}<0.05)$ affected semen parameters.

\section{References}

Abd El-Hamid, I.S. 2019. Effect of adding different levels of caffeine in the extender on some biochemical constituents, enzymatic activities and physical characteristics of chilled and frozen ram semen. Reprod. Domest. Anim., 54(2): 225-233.

Abdelhakeam, A.A., Graham E.F., Varzquez, I.A. 1999. Studies on the presence and absence of glycerol in unfrozen and frozenram semen: fertility trials and the effects of dilution methods

on freezing ram semen in the absence of glycerol. Cryobiology, 28:36-42.

Abulizi Wusiman., Yan-Ping Wan., Kang Ren., Guan-Bin Zhou., Xiang-Wei Fu., Lun Suo., Zhi-Qian Fan., Liang Wang., Shi-En Zhu. 2012 Semen Storage at 23, 4 , or $-196^{\circ} \mathrm{C}$ and its application to artificial insemination in Small-tail Han sheep. Asian J. Anim. Vet. Adv., 7(4): 299-308.

Alcay, S., Gokce, E., Toker, M.B., Onder, N.T., Ustuner, B., Uzabacı, E., Gul, Z., Cavus, S. 2016. Freeze-dried egg yolk based extenders containing various antioxidants improve post-thawing quality and incubation resilience of goat spermatozoa. Cryobiology, 72: 269-273.

Ansari, M.S., Rakha, B.A., Andrabi, S.M.H., Akhter, S. 2010. Usefulness of powdered and fresh egg yolk for cryopreservation of Zebu bull spermatozoa. Reprod. Biol., 10(3): 235240.

Ax, R.L., Dally, M.A., Lenz, R.W., Love, C.C., Varner, D.D., Hafez, B., Bellin, M.E. 2000. Semen evaluation. In: Hafez, B., Hafez, E.S.E., Eds. Reproduction in Farm Animals. 7th ed., 
Lippincott Williams and Wilkins, Philadelphia. 2000, Pp. 365-375.

Badi, A., Benmoula, A., EL Khalil, K., Nasser, B., El Amiri, B. 2018.Effect of age on Boujaâd ram semen quality extended in skim milk and tris egg yolk at $5^{\circ} \mathrm{C}$. Rev. Mar. Sci. Agron. Vét., 6(2): 220-225.

BAO-Tarragó O. F. 2017.Does the bovine cooled semen reduces sperm damage and increases the pregnancy rate in the FTAI?Tese (Doutorado em Ciências), Faculdadede Medicina Veterinária e Zootecnia, Universidade de São Paulo, Pirassunuga.

Evans, G., Maxwell, W.M.C. 1987. Salamon's Artifi cial Inseminationof Sheep and Goats. Butterworths, Sydney. Pp. 107-141.

Fernandez-Abella, D., Preve, M.O., Villegas, N. 2003. Insemination time and dilution rate of cooled and chilled ram semen affects fertility. Theriogenology, 60: 2126.

García, W., Tabarez, A., Palomo, M. 2017. Effect of the type of egg yolk, removal of seminal plasma and donor age on ram sperm cryopreservation. Anim. Reprod., 14: 1124-1132.

Gil, J., Lundeheim, N., Söderquist, L., Rodriíuez-Martínez, H., 2003. Influence of extender, temperature, and addition of glycerol on post-thaw sperm parameters in ram semen. Theriogenology, 59: 1241-1255.

Gil, J., Fierro, S., Olivera-Muzante, J. 2011.Chilled Storage of Ram Semen Improves with the Addition of Egg Yolk and Glycerol to Milk-Based Extenders. Reprod. Dom. Anim., 46(3): 503-507.

Hammerstedt, R.H., Graham, J.K., Nolan, J.P. 1990. Cryopreservation of mammalian sperm: what we ask them to survive. J. Androl., 11: 73-88.

Holt, W.V., 2000. Basic aspects of frozen storage of semen. Anim. Reprod. Sci., 62: 3-22.

Kordan, W., Fraser, L., Wysocki, P., Strzeżek, R., Lecewicz, M., Mogielnicka-Brzozowska, M., Dziekońska, A., Soliwoda, D., Koziorowska-Gilun, M. 2013 Semen quality assessments and their significance in reproductive technology Polish J. Vet. Sci. 16 (4): 823-833.

Malejane,C.M., Greyling,J.P.C., Raito, M.B. 2014.Seasonal variation in semen quality of Dorper rams using different collection techniques. South A. J. Anim. Sci., 44(1): 26-32.

Marco-Jiménez, F., Puchades, S., Mocé, E., Viudes-de-Cartro, M.P., Vicente, J.S., Rodriguez-Martinez, H. 2004. Use of powdered egg yolk vs. fresh egg yolk for the cryopreservation of ovine semen. Reprod. Dom. Anim., 39:438-441.

Maxwell, W.M.C., Salamon, S. 1993. Liquid storage of ram semen: a review. Reprod. Fertil. Dev., 5: 613-638.

Maxwell, W.M.C., Watson, P.F., 1996. Recent progress in the preservation of ram semen. Anim. Reprod. Sci. 42: 5565.

Menchaca, A.,Pinczak, A.,Queirolo, D. 2005. Storage of ram semen at $5^{\circ} \mathrm{C}$ : effects of preservation period and timed artificialinsemination on pregnancy rate in ewes. Anim. Reprod., 2(3):195-198.

Morrier, A., Castonguay, F. and Bailey, J. L. 2002. Glycerol addition and conservation of fresh and cryopreserved ram spermatozoa. Can. J. Anim. Sci.,82: 347-356.

Mortimer, D. 1994. Practical Laboratory Andrology. Oxford University Press, New York, USA. Practical Laboratory Andrology. Oxford University Press, New York, USA. Pp. 66-69.

Ollero, M., Blanco, T.M., Lopez-Perez, M.J., Perez, J.A.C. 1996. Surface changes associated with ram sperm 
cryopreservation reveled by countercurrent distribution in an aqueous twophase system: effect of different cryoprotectant. Journal Chrom., B 680: 157-164.

Pelufo, V., López Armengol,M.F., Malcotti, V., Venturino, A., Aisen, A.G. 2015. Effects of glycerol and sugar mixing temperature on themorphologic and functional integrity of cryopreserved ramsperm. Theriogenology, 83: 144151.

Pervage, S., Hassan, M.R., Ershaduzzaman M., Khandoker, M.A.M.Y. 2009. Preservation of liquid semen and Artificial Insemination in native sheep. J. Bangladesh Agril. Univ., 7(2): 305308.

Purdy, P.H, Mocé, E., Stobart, R., Murdoch, W.J., Moss, G.E., Larson, B., Ramsey, S., Graham, J.K., Blackburn, H.D. 2010. The fertility of ram sperm held for $24 \mathrm{~h}$ at 5 degrees $\mathrm{C}$ prior to cryopreservation. Anim. Reprod. Sci., 118: 231-5.

Rekha A., Zohara B.R, Bari F.Y., Alam M.G.S. 2016. Comparisons of commercial Triladyl and locally manufactured extenders for the chilling of semen and their effects on pregnancy rates after transcervical AI in Bangladeshi Indigenous (Ovis aries) sheep. Anim. Reprod., 13: 735 - 742.

Salomon, S. and Maxwell, W. M. C. 2000. Storage of ram semen. Anim Reprod. Sci., 62: 77-111.

Stefanov, R., Anev G., Abadjieva D. 2015. Effect of different extenders and storage periods on motility and fertility of ram sperm. Mac. Vet. Rev., 38(1): 85-89.

Valente, S.S, Pereira, R.M., Baptista, M.C., Marques, C.C., Vasques, M.I., Pereira, M.V., Horta, A.E., Barbas, J.P. 2010. In vitro and in vivo fertility of ram semen cryopreserved in different extenders. Anim. Reprod. Sci. 117:74-77.

Varişli, O., Taşkin, A., Akyol, N., 2018. Effects of different extenders and additives on liquid storage of Awassi ram semen. Turkish J. Vet. Anim. Sci. 42: $230-242$.

White, I.G. 1993. Lipids and calcium uptake of sperm in relation to cold shock and preservation: a review. Reprod. Fertil. Dev., 5: 639-658.

\section{How to cite this article:}

Yotov, S., M. Karadaev, A. Atanasov, I. Fasulkov, A. Antonov and Kistanova, E. 2019. Effect of Extenders containing Glycerol and Egg Yolk On Motility and Viability of Chilled Ram Semen collected during Non-Breeding Season. Int.J.Curr.Microbiol.App.Sci. 8(05): 588-596. doi: https://doi.org/10.20546/ijcmas.2019.805.068 